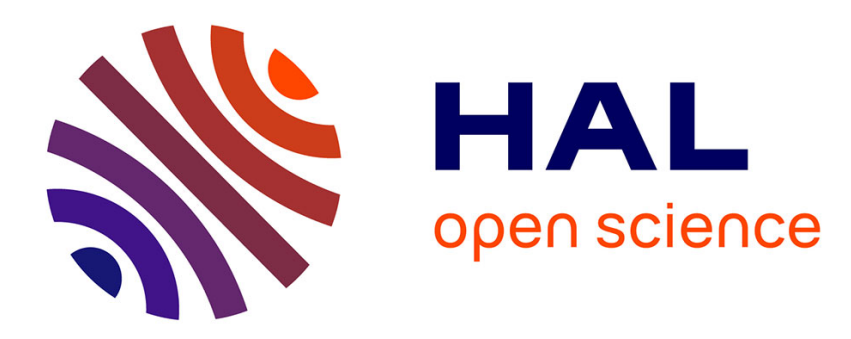

\title{
Thermodynamics Aspects of Chemical Vapour Deposition of V-VII Group Metals and their Alloys with Tungsten
}

\author{
Y. Lakhotkin
}

\section{- To cite this version:}

Y. Lakhotkin. Thermodynamics Aspects of Chemical Vapour Deposition of V-VII Group Metals and their Alloys with Tungsten. Journal de Physique IV Proceedings, 1995, 05 (C5), pp.C5-199-C5-204. 10.1051/jphyscol:1995522 . jpa-00253847

\section{HAL Id: jpa-00253847 https://hal.science/jpa-00253847}

Submitted on 1 Jan 1995

HAL is a multi-disciplinary open access archive for the deposit and dissemination of scientific research documents, whether they are published or not. The documents may come from teaching and research institutions in France or abroad, or from public or private research centers.
L'archive ouverte pluridisciplinaire HAL, est destinée au dépôt et à la diffusion de documents scientifiques de niveau recherche, publiés ou non, émanant des établissements d'enseignement et de recherche français ou étrangers, des laboratoires publics ou privés. 


\title{
Thermodynamics Aspects of Chemical Vapour Deposition of V-VII Group Metals and their Alloys with Tungsten
}

\author{
Y.V. Lakhotkin
}

Institute of Physical Chemistry, Russian Academy of Sciences, Leninsky pr. 31, 117915, Moscow, Russia

\begin{abstract}
The composition of the gas and solid phases for the metal (V, Nb, Ta, Mo, W, Re)-fluorinehydrogen (Me-F-H) systems in the temperature range $400-2000 \mathrm{~K}$ at pressures of $1.3 \times 10^{5} \mathrm{~Pa}$ and $2 \mathrm{kPa}$ and for fluoride to hydrogen ratios from 1:3 to $1: 100$ have been calculated using complete basic data of thermochemical constants of the fluorides in different valent and structural states. It was established that the moving forces (supersaturation) of the metal crystallization in these systems decrease in the following order: Re, W, Mo, Nb, Ta, V. Thermodynamics of tungsten solid solutions in V, Nb, Ta, Mo and Re was considered in the frames of the crystallization theory. It was shown that the temperature of tungsten deposition from the Me-F-H systems in the CVD processes increases with the addition of Re, W. Mo, V, $\mathrm{Nb}$, Ta fluorides (in the order of increment).
\end{abstract}

\section{INTRODUCTION}

The chemical vapor deposition (CVD) of metals by the hydrogen reduction of their fluorides is known as one of the perspective technique for the production of high quality refractory metals [1]. The CVD of tungsten has been more extensively studied due to unique combination of its features such as low deposition temperature $(750-900 \mathrm{~K}$ ), high growth rate (up to $5 \mathrm{~mm} / \mathrm{h}$ ), a good purity and high density of tungsten deposit [2]. Up to now there is a great interest to CVD tungsten alloys due to their physical-mechanical properties [3].

The thermodynamic analysis of the CVD processes is useful to define the optimal deposition conditions. The understanding of the gas phase phenomena controlling the metals and alloys deposition requires the knowledge of the gas mixture compositions and surface kinetics which lead to the deposit growth. This work was done to define the compositions of gas and solid phases as the result of the equilibrium of the hydrogen and metal fluorides for the metals of VB group (V, Nb, Ta), VIB group (Mo, W) and VII group (Re). A particular attention is paid to the theoretical aspects of tungsten alloys growth.

The accuracy of thermodynamic analysis depends on the completeness and the reliability of thermochemical data. Unfortunately, a limited number of the transition metal fluorides have been characterized thermochemically or have been studied by a spectroscopic technique. The experimental data were completed with the evaluated thermochemical constants for fluorides in different valent and structural states. The constants were obtained by the interpolation procedure based on the periodic law 14]. The thermochemical properties of known ordinary and polymeric fluorides of the metals were summarized in [4]. The ligands of polymer fluorides are bonded by single or double fluorine bonds or metallic bonds $[5,6]$. 


\section{RESULTS}

The equilibrium analysis of the metal-fluorine-hydrogen $(\mathrm{Me}-\mathrm{F}-\mathrm{H})$ systems for the temperature range $400-2000 \mathrm{~K}$, total pressures of $1.3 \times 10^{5} \mathrm{~Pa}$ and $2 \mathrm{kPa}$ and for fluoride to hydrogen ratios from 1:3 to $1: 100$ have been calculated using a special procedure based on the search of entropy extremum for the polycomponent mixture. All experimental and calculated thermochemical constants of the fluorides and the characteristics of the fluoride phase transitions were involved into the set of the data. The equilibrium compositions of $\mathrm{Me}-\mathrm{F}-\mathrm{H}$ systems $(\mathrm{Me}=\mathrm{V}, \mathrm{Nb}, \mathrm{Ta}, \mathrm{Mo}$, $\mathrm{W}, \mathrm{Re}$ ) for the optimal total pressure and for the optimal reagent ratio are presented in Fig. 1. The variation of the external conditions (total pressure and fluoride to hydrogen ratio) influence the gas phase composition according to the law of mass action and Le Chatelier principle.

The gas phase composition depends on both the heat of the fluoride formation and the vaporization heat of the fluorides. The thermodynamic analysis of Me-F systems shows that highest fluorides of the metals are stable at temperatures up to $2000 \mathrm{~K}$. The gas lower-valent fluoride concentrations, which depend upon the metal place in the periodic system, rise with the increase of atomic number within each group and decrease with the increase of atomic number within each period. Thus tantalum fluorides are most strongly bonded halides among considered fluorides.

Nevertheless the vaporization temperature of fluorides are varied depending upon the metal place in the periodic system in opposite direction than the gas lower-valent fluorides concentration. The most refractory fluorides are VF2 and VF3 (above $1500 \mathrm{~K}$ ), the lower-valent fluorides of $\mathrm{Nb}$ and Mo possess the mean vaporization temperatures (900-1100 K). The lowervalent fluorides of tantalum, tungsten, rhenium have the lowest vaporization temperature (500-550 $\mathrm{K})$.

As it shown in Fig. 1, the concentrations of the gas fluorides depend upon the metal place in the periodic system and rise with the atomic number increase for each groups and decrease with the atomic number increase for each periods. The source of VB group metals arisen from $\mathrm{Me}-\mathrm{F}-\mathrm{H}$ system are highest fluorides and polymers. The VI group metals are the product of hexa-, pentaand tetrafluoride decomposition, but all known rhenium fluorides produce the metallic deposit.

Fig.2 presents the equilibrium yield of metals from the mixtures of their fluorides with hydrogen as a function of the temperature. It is shown that metallic Re, Mo, W may be deposited from Me-F-H systems at temperatures above $300 \mathrm{~K}$. Yields of $\mathrm{Nb}$ and $\mathrm{Ta}$ were varied in the temperature range from $800 \mathrm{~K}$ to $1300 \mathrm{~K}$. Metallic $\mathrm{V}$ may not be deposited from Me-F-H system until $1700 \mathrm{~K}$ due to high sublimation temperature of VF2 or VF3. It was established that the moving forces (supersaturation) of metal crystallization in Me-F-H systems increase in the order for following metals: $\mathrm{Re}, \mathrm{Mo}, \mathrm{W}, \mathrm{Nb}, \mathrm{Ta}, \mathrm{V}$. This thermodynamic results are in agreement with the experimental data reviewed in [1-3].

A thermodynamic of alloy deposition is often considered as a heterogeneous equilibrium of gas and solid phases, in which solid components are not bonded chemically or form the solid solution. The calculation of the solid solution composition requires the knowledge of the entropy and the enthalpy of mixing. The entropy of mixing is easily calculated but the enthalpy of mixing is usually determined by the experimental procedure. For tungsten alloys, these parameters are estimated only theoretically [7]. A partial enthalpy of mixing can be approximated as follows:

$$
\Delta \mathrm{H}_{\mathrm{m}}=\left(\mathrm{h}_{1, \mathrm{i}}+\mathrm{h}_{2, \mathrm{i}} \mathrm{T}+\mathrm{h}_{3, \mathrm{i}} \mathrm{x}_{\mathrm{i}}\right) \times\left(1-\mathrm{x}_{\mathrm{i}}\right)^{2},
$$

where $h_{1, i}, h_{2, i}, h_{3, i}$ - polynomial's coefficients, $T$ - temperature, $x_{i}$ - mole fraction of solution component.

The surface properties of tungsten are sharply different from the bulk properties due to strongest chemical interatomic bond. Therefore, it is expediently to include the crystallization stage in the thermodynamic consideration, because the crystallization stage controls the tungsten 

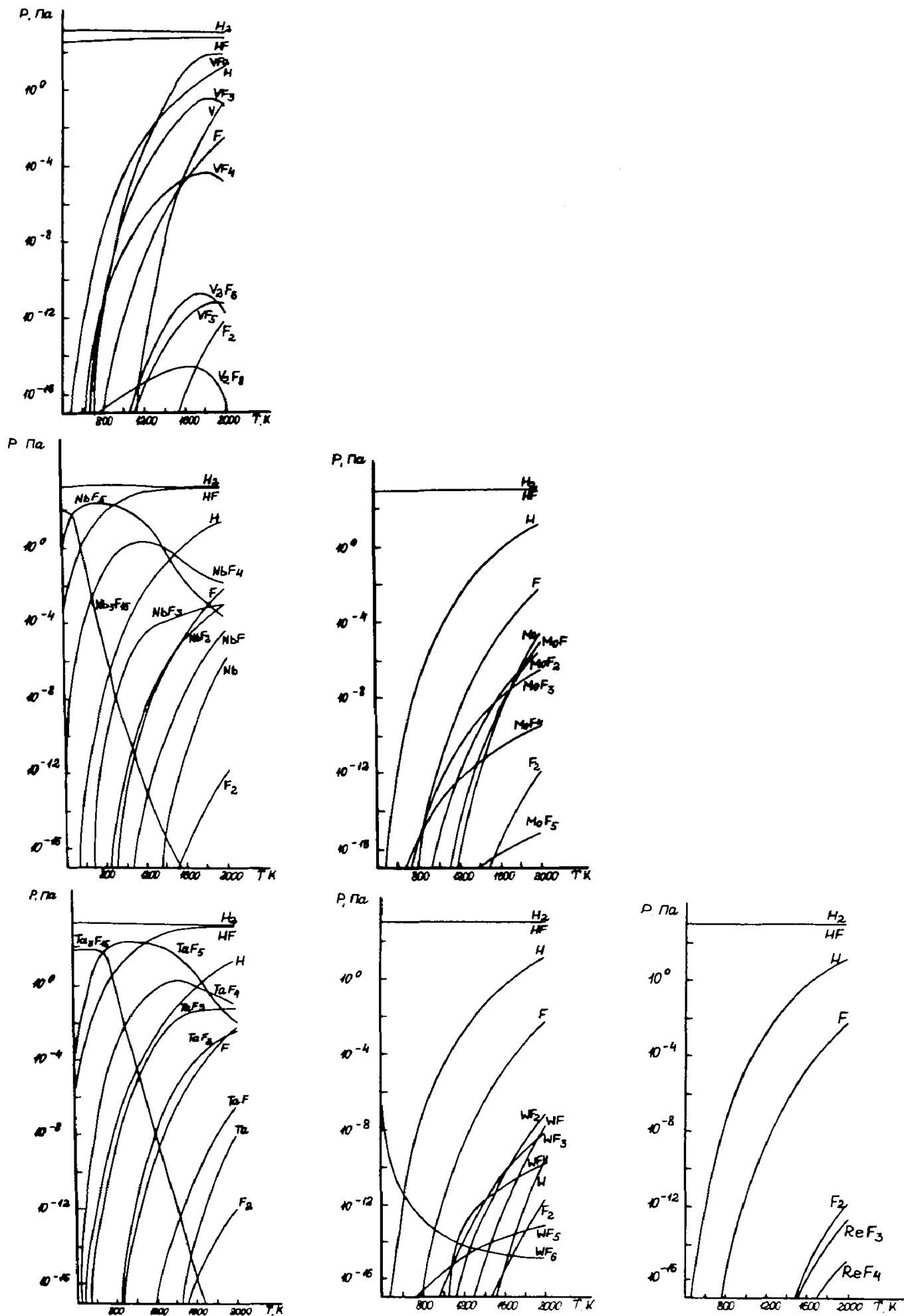

Figure 1: Temperature influence on equilibrium composition of gas phase in metal ( $V, N b, T a, M o, W, R e)-$ fluoride-hydrogen systems for rotal pressure $2 \mathrm{kPa}$ and for fluoride-indrogen ratio $1: 10$. 
growth in wide interval of deposition conditions. To determine the enthalpy of mixing of surface atoms we use the results on the adsorption of transition metals on (100) tungsten plane [8]. The crystallization energy can be determined as the difference between the molar enthalpy of the transition metal sublimation from (100) tungsten surface and the sublimation energy of pure metal. These values are presented in the Table 1 in terms of polynomial's coefficients, which were estimated in the case of the infinitely dilute solution. The data predict that the co-crystallization of tungsten with $\mathrm{Nb}, \mathrm{V}, \mathrm{Mo}$, Re will be perform more easy then the crystallization of unalloyed tungsten. The crystallization W-Ta alloys has the reverse tendency. Certainly the synergistic effects will influence the composition of gas and solid phases.

Table 1

Excess partial "enthalpy of mixing" atoms for crystallization of $\mathrm{W}$-Me binary solid solution and $\mathrm{h}_{\mathrm{i}}$ polynomial's coefficients for $x_{i}=0-0.0625$ and $T=298-2500 \mathrm{~K}$

\begin{tabular}{|c|c|c|c|c|c|}
\hline No & $\mathrm{Me}$ & $\begin{array}{c}\Delta \mathrm{H}^{0} \mathrm{~m}_{\mathrm{i}}, 298 \mathrm{~K} \\
\mathrm{x}_{\mathrm{i}}=0\end{array}$ & $\begin{array}{c}\mathrm{h}_{1, \mathrm{i}} \\
\mathrm{kJ} / \mathrm{mol}\end{array}$ & $\begin{array}{c}\mathrm{h}_{2, \mathrm{i}} \\
\mathrm{kJ} / \mathrm{mol}\end{array}$ & $\begin{array}{c}\mathrm{h}_{3, \mathrm{i}} \\
\mathrm{kJ} / \mathrm{mol}\end{array}$ \\
\hline 1 & $\mathrm{~W}$ & 0 & 0 & 0 & 0 \\
& $\mathrm{Ta}$ & $36.4 \pm 10.9$ & 36.4 & -0.00042 & 72.7 \\
\hline 2 & $\mathrm{~W}$ & 0 & 0 & 0 & 0 \\
& $\mathrm{Nb}$ & $-225.7 \pm 50.2$ & -225.7 & -0.00025 & -451.4 \\
\hline 3 & $\mathrm{~W}$ & 0 & 0 & 0 & 0 \\
& $\mathrm{~V}$ & $-434.7 \pm 50.2$ & -434.7 & -0.00017 & -1304.2 \\
\hline 4 & $\mathrm{~W}$ & 0 & 0 & 0 & 0 \\
& $\mathrm{Mo}$ & $-467.7 \pm 10.9$ & -467.7 & -0.00117 & -935.5 \\
\hline 5 & $\mathrm{~W}$ & 0 & 0 & 0 & 0 \\
& $\mathrm{Re}$ & $-220.3 \pm 10.9$ & -220.3 & -0.00058 & -440.5 \\
\hline
\end{tabular}

Therefore the thermodynamic calculation for gas and solid composition of W-Me-F-H systems were carried out for the following cases:

(1) without the mutual interaction of solid components;

(2) for the formation of ideal solid solution;

(3) for the formation of nonideal solid solution;

(4) for the interaction of binary solution components on the surface.

The temperature influence on the conversion of VB group metal fluorides under their addition to the tungsten hexafluoride-hydrogen mixture is presented in Fig.3. If the metal interaction in the solid phase is not taken into account, the vanadium pentafluoride is reduced by hydrogen to lower-valent fluorides only. It should be noted that metallic vanadium can be deposited at temperatures above $1900 \mathrm{~K}$. Equilibrium fraction of NbF5 conversion achieves $50 \%$ at $1400 \mathrm{~K}$, one of TaF5 - at $1600 \mathrm{~K}$ (Fig. 3, curves 1).

The thermodynamic consideration of ideal solid solution shows that tungsten-vanadium alloys might deposit in high temperature range only $(\mathrm{T}>1400 \mathrm{~K}$ ) and metallic vanadium is deposited with the lower-valent fluorides of vanadium. The beginning of formation of $\mathrm{W}-\mathrm{Nb}$ and W-Ta ideal solid solution are shifted to lower temperature by about $100 \mathrm{~K}$ (Fig.2, curves 2 ) in comparison with the case (1). It should be noted, that the calculation results performed for cases (2) and (3) (for ideal and nonideal solid solution) are almost identical due to the small quantity of enthalpy of mixing presented in [7].

Taking into account the interaction of component alloys during crystallization. the formation of $\mathrm{W}-\mathrm{V}$ and $\mathrm{W}-\mathrm{Nb}$ alloys are possibly taking place at the temperatures above $300 \mathrm{~K}$. 




Figure 2: Yield of metals $(\mathrm{V}, \mathrm{Nb}, \mathrm{Ta}, \mathrm{Mo}, \mathrm{W}, \mathrm{Re})$ from the equilibrium mixtures of their fluorides with hydrogen $(1: 10)$ as a function of the temperature.



Figure 3: Equilibrium yields of VB group metals from the mixtures of their pentafluorides, tungsten hexafluoride and hydrogen (MeF5:WF6:H2 $=0.06: 1: 10)$ for $2 \mathrm{kPa}$ as a function of the temperature.

1. without the interaction of solid components;

2. for the formation of ideal or nonideal solid solution;

3. for the interaction of binary solution components on the growing surface. 
Temperature boundary showed in Fig. 3 is shifted in reverse direction for the W-Ta system (Fig.3, curves 3).

The influence of rhenium and molybdenum on the equilibrium yield of tungsten in the MeW-F-H systems is proposed to be observed for W-Re and W-Mo alloy deposition. The ReF6 addition to the gas mixture with WF6 increases insignificantly the yield of tungsten in spite of strong atom interaction during the crystallization according to thermodynamic calculations. This effect is still smaller for the case of W-Mo co-deposition. However equilibrium yield of metals for their co-deposition with tungsten and the energy of the interaction of metallic components during the crystallization have the common tendency. The knowledge of refined data on surface process energies will allow us to obtain a more realistic situation.

\section{CONCLUSIONS}

1. The systematic investigation of equilibrium states in the Me-F, Me-F-H (Me $=\mathrm{V}, \mathrm{Nb}$, $\mathrm{Ta}, \mathrm{Mo}, \mathrm{W}, \mathrm{Re}$ ) systems was carried out. It was demonstrated that the equilibrium concentrations of highest fluorides in the Me-F systems are determined by the place of metal in the periodic table. Those rise with the increase of atomic number within each group and decrease with the increase of atomic number within each period. The lower-valent fluoride concentrations have the opposite tendency. It was shown that the equilibrium yield of Re, Mo, W deposition from the Me$\mathrm{F}-\mathrm{H}$ systems achieve $100 \%$ at room temperature, equilibrium yield of $\mathrm{Nb}$, $\mathrm{Ta}$ and $\mathrm{V}$ deposition at temperatures above $1300 \mathrm{~K}, 1600 \mathrm{~K}$ and $1700 \mathrm{~K}$ respectively.

2. The gas and solid compositions of the W-Me-F-H systems were calculated by taking into account the formation of ideal, nonideal solid solution, the mechanical mixture of solid components and the atom interaction on the growing surface during the crystallization. It was established ihat only an introduction in the thermodynamic calculation of atom interaction on the growing surface, which increases in the following sequence: $\mathrm{Ta}, \mathrm{W}, \mathrm{Re}, \mathrm{Nb}, \mathrm{V}, \mathrm{Mo}$, results in a rise of yield of VB group metals under their co-deposition with tungsten, excepting W-Ta system. This may explain the experimentally observed in $[1,3]$ tungsten yield rise under its alloying with rhenium and molybdenum.

3. The thermodynamic analysis, performed by taking into account the formation of solid lower-valent fluorides and excess enthalpy of atom interaction during crystallization, showed that the moving force of CVD of the alloys from the W-Me-F-H systems (the supersaturation in these systems) increase in order: $\mathrm{Ta}, \mathrm{Nb}, \mathrm{V}, \mathrm{Mo}, \mathrm{W}, \mathrm{Re}$.

\section{References}

[1] Korolev Yu.M., Stolyarov V.I., Vosstanovlenie ftoridov tugoplavkikh metallov vodorodom (Metallurguij, Moskva, 1981) 184 p. (in Russian).

[2] Krasovski A.I., Chuzshko R.K., Tregulov V.R., Balakhovski O.A., Ftoridni process poluchenij volframa (Nauka, Moskva, 1981) 260 p. (in Russian).

[3] Lakhotkin Yu.V., Krasovski A.I., Volfram-renievie pokritij (Nauka, Moskva, 1989) 158 p.

(in Russian).

[4] Malandin M.B., Lakhotkin Yu.V., Kuzmin V.P., Problemi fizicheskogo metallovedenij

(MIFI, Moskva, 1991) pp 35-47. (in Russian).

[5] Politov Yu.A., Alikhanyan A.S., Butzki V.D. et al., DANN SSSR 2 (1989) 897-899 (in

Russian).

[6] Pervov V.S., Koordinasionnaij chimij 6 (1980) 1495-1497 (in Russian).

[7] Kaufman L., Bernstein Kh., Raschet diagramm sostoijnij s pomoschyu EVM (Mir, Moskva, 1972) 328 p. (in Russian).

[81 Plummer E.W., Rhodin T.N., J. Chem. Phys. 49 (1968) 3479-3496. 